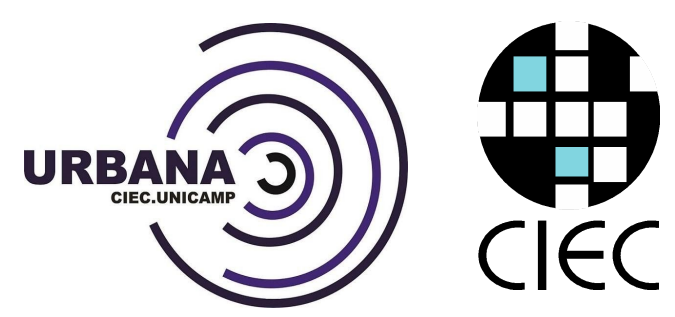

URBANA: Revista Eletrônica do Centro Interdisciplinar de Estudos sobre a Cidade

Germana Konrath; Paulo Reyes

germana.konrath@gmail.com; paulo.reyes@ufrgs.br | Universidade Federal do Rio Grande do Sul

\title{
As margens espacializadas de Francis Alÿs
}

Francis Alÿs' spacialized borders

Los márgenes espacializados de Francis Alÿs

Resumo | Abstract | Resumen

\section{Atravessando fronteiras}

Espessar as linhas, questionar os acordos, borrar os traçados, espacializar as bordas, permanecer nas margens, tornar-se estrangeiro, ser outro, passar ao outro, habitar o outro. Entre tantas leituras possibilitadas pela trajetória artística de Francis Alÿs, como as elencadas acima, nos deteremos aqui em suas ações ritualísticas destacadamente coletivas - realizadas com a participação de voluntários - que tomam corpo em situações marginais ou fronteiriças: ações estéticas que produzem ações políticas. Partimos de quatro trabalhos do artista, datados de 2002 a 2008, que formam uma espécie de marco em sua poética. Segundo Alÿs, trata-se do 
momento em que ele passa de uma percepção vinculada à ideia de que fazer algo pode levar a nada - como indica seu projeto Paradoja de la praxis I, a veces hacer algo no lleva a nada, de 1997 - para um entendimento de que, talvez, fazer algo possa levar a outra coisa como sugere o subtítulo de sua ação The green line: sometimes doing something poetic can become political and sometimes doing something political can become poetic, de 2004. Nos interessa assim debater essa possibilidade, no contexto urbano, de algo poético se tornar político e vice-versa.

Nascido na Antuérpia Francis de Smedt, formado em arquitetura com doutorado em urbanismo obtido em Veneza no início dos anos 1980, Francis viaja em uma missão para o México em 1986 fugindo do serviço militar belga. Acaba permanecendo naquele país, onde começa sua trajetória poética: caminha, observa, sinaliza situações existentes, inventa narrativas e provoca percepções inaugurais a partir de seus rituais urbanos e agenciamentos territoriais. Muda seu nome para Francis Alÿs e, desde então, torna-se cada vez mais mexicano e cada vez mais artista.

Desde então opera no espaço que cria entre fronteiras, tanto conceituais quanto geográficas: entre arquiteto e artista, entre observador e participante, entre local e estrangeiro. A seu ver, todos esses projetos e tempos "entre" tentam fazer parte de uma grande narrativa, cujo produto final importa menos que o processo. A ocupação do espaço urbano para Alÿs é, antes de mais nada, uma condensação de tempos que se adaptam à cada nova situação. São ações táticas, nômades, que desconhecem ou burlam os limites impostos.

Fazendo jus a esse modus operandi artístico, a poética de Alÿs será aqui atravessada por constelações conceituais que, mais do que compor definições fixas, trabalham em movimento dinâmico. Podemos citar contribuições teóricas da dupla Gilles Deleuze e Félix Guattari acerca do binômio liso-estriado e de desterritorializar-reterritorializar; a relação entre estética e política 
para Jacques Rancière e a distinção entre tática e estratégia em Michel de Certeau - atualizadas para o contexto latino americano contemporâneo em que Alÿs trabalha mais intensamente. Em termos de recorte, a ênfase será na atuação de Alÿs junto ao espaço urbano comum: no tensionamento de seus limites e na possibilidade de sua criação em situações marginais a partir de rituais coletivos.

Em diversos projetos, o artista se vale de recursos poéticos para elaborar o que ele próprio nomeia de fábulas, forjando novas identidades e situações dissensuais - sempre atos políticos conforme o cenário urbano onde as insere. Suas ações simples e seus registros sempre porosos e parciais ajudam a compor diversas narrativas abertas, que atravessam o tempo como um mito que se alastra, operando taticamente tanto no presente quanto no pensamento projetivo de futuro e na memória que inventa passados. Pode-se dizer que Alÿs realiza o que outrora os romanos faziam em rituais de fundação ou expedições diplomáticas, a partir de marchas que ocorriam primeiro dentro do próprio território, depois na fronteira e, finalmente, no território estrangeiro. A esse respeito Certeau escreve "a ação ritual se efetua antes de toda ação civil ou militar porque se destina a criar o campo necessário para as atividades políticas ou bélicas" (1994, p. 210).

Seria esse o primeiro papel do relato para Certeau: abrir um teatro que legitimaria as ações efetivas posteriores - muito similar à defesa de Rancière quanto ao papel da ficção em nossa era estética, gerando efeitos no real. Segundo Rancière, "o real precisa ser ficcionado para ser pensado" (2009, p. 58). A esse respeito, sublinhando especialmente suas ações em situações de fronteira, Alÿs questiona:

É possível uma intervenção artística verdadeiramente trazer uma maneira imprevista de pensar ou é mais uma questão de criar uma sensação de 'falta de sentido' que mostra o absurdo da situação? (...) Pode um ato absurdo provocar uma transgressão que faça você abandonar os pressupostos padrão sobre uma situação, como as fontes de conflito? Podem estes tipos de atos artísticos trazer possibilidades de mudança? Como a arte pode 


\section{Da areia para o mar}

Chegando a Ventanilla, uma paisagem se descortina entre montanhas: formado por campos áridos um quase deserto apresenta-se em tons que vão do bege ao cinza. Poeira e areia cobrem o horizonte e invadem as cabanas improvisadas, as moradias precárias e as estruturas inacabadas de um esqueleto de cidade que parece ter sido semi-soterrada ou estar prestes a emergir do solo. Não corresponde, certamente, à nossa imagem tradicional de urbe contemporânea. O local, sem luz elétrica nem água encanada, poderia ser um cenário distópico ou pós-apocalíptico, mas é um distrito de Lima: faz parte de sua periferia.

Ali vivem mais de 70 mil pessoas em 2002, mesmo ano da derrocada de Alberto Fujimori, após duas décadas à frente da ditadura peruana. Naquele ano e lugar, 500 voluntários entre moradores locais e estudantes universitários se unem, munidos de pás, para mover uma duna. A ideia é que, em linha, cada um ocupe seu metro de duna e desloque a areia que estiver à sua frente. Todos em conjunto, num ritmo coletivo, exaustivo, avançam. Ao anoitecer calcula-se que a intenção de mover a duna em algumas polegadas tenha sido atingida. No final do dia, nenhum centavo ganho, 500 voluntários cansados e uma duna de meio quilômetro que, em poucos segundos e ao sabor dos ventos, poderá recuar à posição inicial. Nenhum dos moradores foi realocado; ao contrário, seguem fazendo parte dos $31 \%$ da população limenha que vive em pueblos jóvenes, como são chamados pelos peruanos esses povoados equivalentes a nossas favelas. Alÿs e seus colaboradores, no entanto, pareciam realizados. 


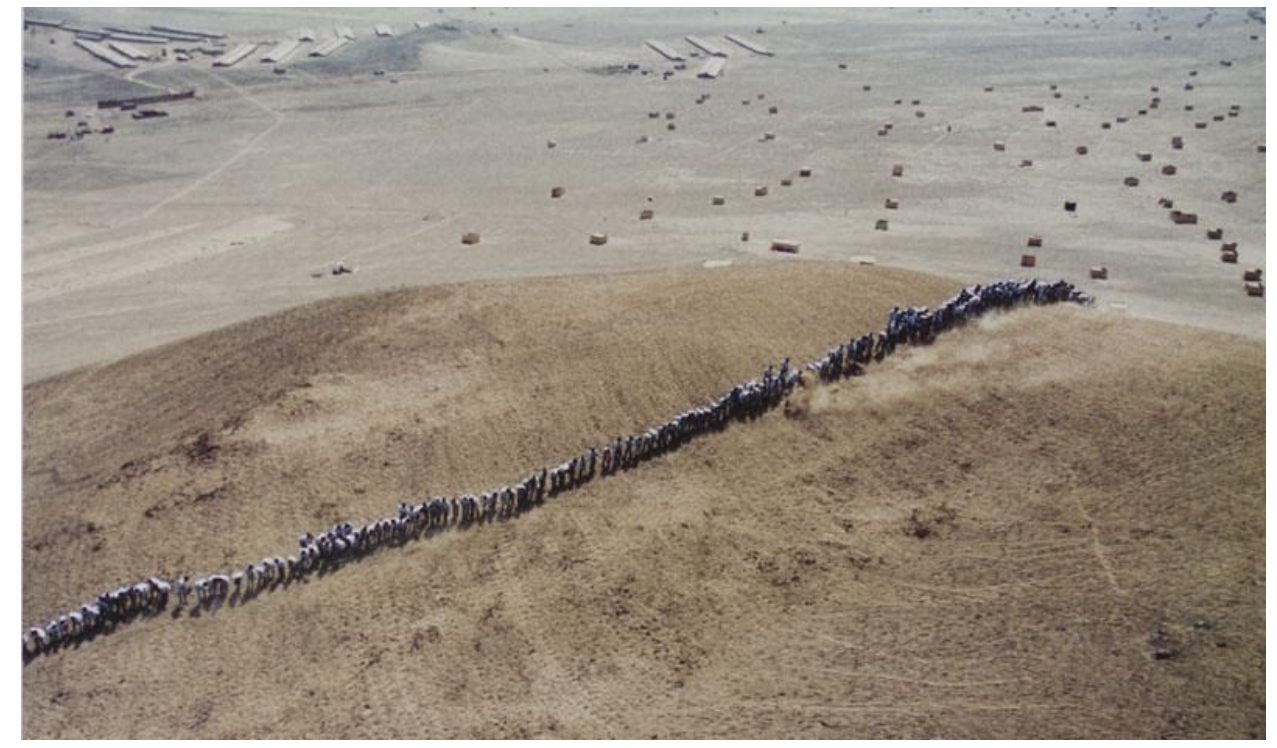

Figura 1: Francis Alÿs em colaboração com Cuauhtémoc Medina e Rafael Ortega. Cuando la fe mueve montañas, 2002. Documentação fotográfica de um evento. Fonte: FERGUSON; FISHER; MEDINA, 2007, p. 53.

A partir do projeto Cuando la fe mueve montañas, Alÿs parte para ações mais declaradamente coletivas e, quiçá, mitológicas. O artista volta-se para a periferia, caminha em direção às bordas da cidade, chega aos limites do urbano. Ao falar do local que escolheu, Alÿs frisa a importância de Ventanilla como ícone de uma cidade convulsionada, de tensão política e socioeconômica, mas também cultural e urbana. Segundo ele, "Lima foi empurrando essas dunas ao longo de décadas. Este constante alargamento das extremidades da cidade é o resultado de sua conversão inevitável em uma megalópole" (ALŸS; MEDINA, 2005, p. 49). Processo que naturalmente a faria exilar sua paisagem, nas palavras do artista. As metrópoles latino-americanas - e tantas outras -, converteram-se numa sobrecarga para si mesmas: cidades que pesam sobre os homens e sobre o solo.

Se essas imagens podem acionar tanto pensamentos utópicos como distópicos, Alÿs e seus companheiros parecem indicar seu interesse pelo primeiro tipo. No livro intitulado Numa dada situação, seu companheiro de trabalho e curador, Cuauhtémoc Medina, faz uma pequena lista de lições da deriva e enumera: “1 - 
sem barro não há texto. 2 - sem paisagem não há conto. 3 - sem solo não há sonho" (MEDINA in ALŸS, 2010, s.p.). Cuando la fe mueve montañas anuncia um trabalho de esperança projetual, feito de paisagem e barro. Os números inflamados corroboram para essa aura mítica em torno da ação - um ritual quase messiânico.

Segundo o artista, "era uma situação que demandava uma resposta épica: infiltrar uma alegoria social naquelas circunstâncias parecia mais apropriado do que a participação em um exercício artístico." (ALŸS; MEDINA, 2005, p. 51). Alÿs criou um pequeno roteiro que consistia em convidar voluntários para deslocarem em $10 \mathrm{~cm}$ uma duna de areia durante um dia de trabalho. Sem que houvesse nenhum desenho além da linha inicial, nenhuma quantidade mensurável ou resultado objetivo, o artista conseguiu persuadir uma comunidade.

Para ele, "um dos motivos fundamentais do projeto foi abordar o modo como a falta de planejamento é, apesar de tudo, a matriz do tecido urbano latino-americano" (ALŸS; MEDINA, 2005, p. 53). À revelia dos ideais do planejamento urbano, destacadamente de cidades racionalistas com seu território dividido em parcelas conforme suas funções - trabalhar, morar, circular e divertir-se -, as periferias se multiplicam. A partir de uma distribuição dispersa, aparentemente caótica, mas resultante de forças de coação em alto grau pré-determinadas pela estratégia, configuram-se cinturões precários nas bordas da cidade. Sua falta de estrutura tanto física quanto simbólica, a escassez de equipamentos e de espaços de convivência não seria uma reação imprevisível, outrossim o resultado de um processo nomeado por Lefebvre (2008) de urbanização desurbanizada. Ao ver-se confrontado com aquela realidade, Alÿs busca produzir espaços outros - nem crítica niilista, nem intervenção autoral - algo insurgente.

Nesse ritual, Alÿs transforma o desperdício em excesso: de força, de participantes, de pontos de vista, alteridades e expectativas. Como disserta Jean Fisher ao falar do trabalho, "talvez arte seja um 
excesso de vida" (FERGUSON; FISHER; MEDINA, 2007, p. 117). O artista descortina a falta de sentido daquela classificação imposta à Ventanilla de miséria social. Não pretende estetizar nem preencher o vazio, que pode ser um esvaziamento das cidades, a ausência de significado de nossas rotinas ou a transformação de nosso tempo em um conceito alienante de trabalho. Alÿs atua a partir de uma situação real e nela permite canalizar as energias e esperanças para criar novos sentidos partilhados e instituir um mundo ainda não configurado, mas que o artista instaura a partir de uma condição de possibilidade. Dessa vez não opera a partir de um espaço público, Alÿs provoca a comunidade a criar o seu espaço público.

Para Certeau, "o discurso que leva a crer é aquele que priva do que impõe, ou que jamais dá aquilo que promete. Muito longe de exprimir um vazio, de descrever uma falta, ele o cria. Dá lugar a um vazio" (1994, p. 186). Parece ser esse o caso de Cuando la fe mueve montañas: um ritual gerador de vazio a partir de uma situação saturada ao extremo. Certeau segue descrevendo essa operação tática em que o vazio permite a criação de espaços de jogo que o tornam habitável, justamente naqueles lugares onde a estratégia gerou uma sobrecarga, tornando-os sufocantes. A partir da ação artística, a comunidade areja aquela lugar, o torna um espaço respirável.

Seguindo seu texto, Certeau indica como a estratégia busca rapidamente reaprender esses espaços de jogos, de rituais e de mitos, classificando-os pejorativamente como superstições. O autor critica essa postura e descreve as "camadas semânticas supererrogatórias que se insinuam, 'a mais' e 'demais', e alienam num passado ou numa poética uma parte dos terrenos que são reservados pelos promotores de razões técnicas e rentabilizações financeiras" (1994, p. 187). Certeau defende que espaços lúdicos e míticos ou atos como contar lendas são caracterizados, ao mesmo tempo, por deslocamentos e condensações, práticas inventoras de espaços. Postula ainda que os relatos diversificam a história, de tal 
modo que a memória seria um antimuseu, justamente por não ser apreensível nem localizável. É essa a intenção de Alÿs quando inventa fábulas e, se registra suas ações através de diferentes mídias, é para que esses relatos possam circular, alastrando seu campo de atuação para além dos tradicionais limites do meio artístico.

Segundo o artista “nesse momento se cria uma alegoria, uma fábula. A qualidade universal de uma alegoria facilita o processo de exportação, para além do sítio de produção; mas localmente a ação se refere a uma realidade imediata e atual" (ALŸS; MEDINA, 2005, p. 71). Num esforço quixotesco e absurdo, Alÿs constrói uma narrativa que revela a falta de sentido de uma determinada situação, e com isso, a desloca geográfica e metaforicamente. Ao mover o solo, desterritorializa certezas, desestabiliza posições, altera a cartografia local e permite que um novo lugar, talvez um utopos, insurja. Rancière afirma, acerca dessas práticas estéticas, que se tratam de "sistemas das formas que a priori determinam o que se vai experimentar." (RANCIÈRE, 2007 apud CANCLINI, 2012, p. 135).

Dois anos mais tarde, o artista retoma certos movimentos do projeto desenvolvido em Lima, dessa vez respondendo ao contexto de seu habitat. Na ação, intitulada Barrenderos, Alÿs propõe a garis do centro da Cidade do México uma mudança em seu cotidiano. Ali, diariamente, centenas de ambulantes e camelôs montam suas barracas - numa prática tradicional da cultura mexicana de comércio de rua. À noite, quando os vendedores saem do centro levando consigo seus carrinhos, tendas e produtos, sua presença é substituída por resíduos - os refugos são como um testemunho de sua existência. Durante as madrugadas entram em ação os garis que transformam esses restos em limpeza, numa rotina diária: presença-resíduo-limpeza-ausência. O ciclo é interrompido na noite em que Alÿs convida os varredores encontrados no caminho para que se organizem em grupo e que, em linha, empurrem os restos com suas vassouras, a fim de formar um bloco de lixo único, grande e denso, até o ponto em que não mais consigam movê-lo. 


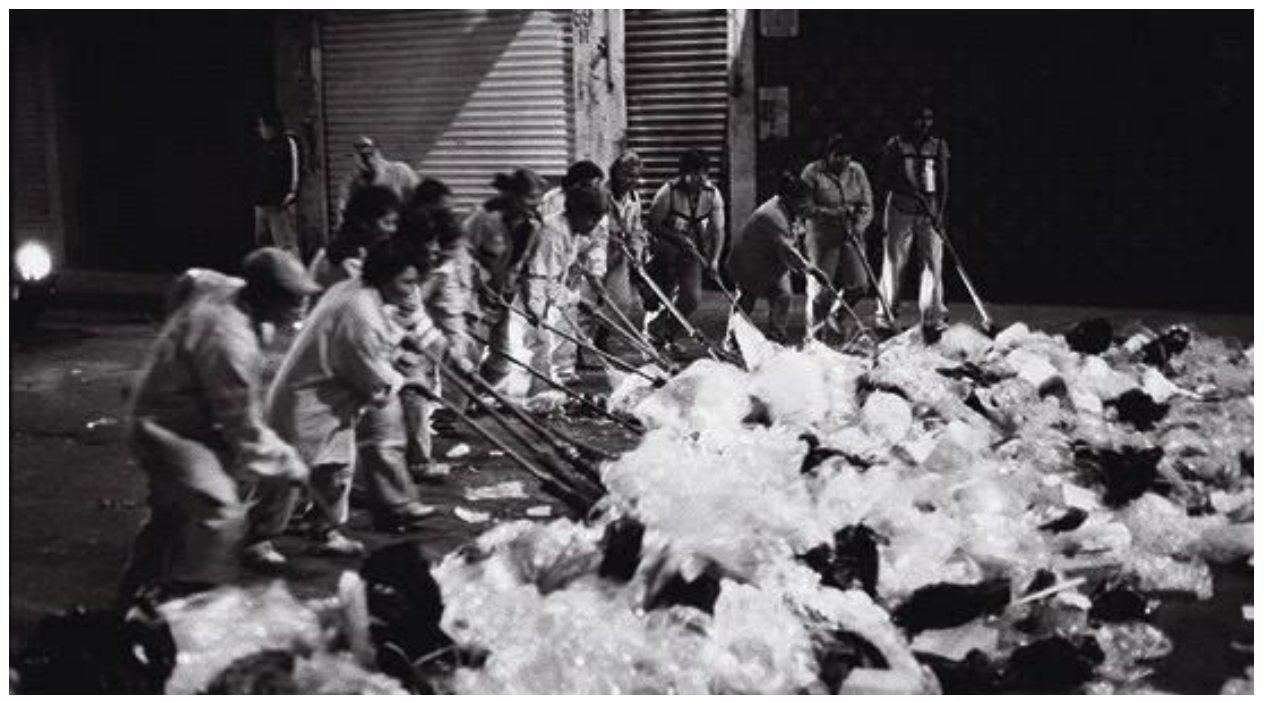

Figura 2: Francis Alÿs em colaboração com Julien Devaux. Barrenderos, 2004. Still de vídeo.

Fonte: FERGUSON; FISHER; MEDINA, 2007, p. 50.

Novamente temos uma notação artística sobre os processos de expulsão do proletariado da vida urbana e de seus pólos de poder. É irônico pensar no título da ação em relação a esses processos de "revitalização" recorrentes em toda América Latina que atendiam, no começo do século XX, por nomes como plano de melhoramentos, embelezamento, saneamento ou higienização urbana. Alÿs nos mostra o avesso do projeto de "requalificação" do centro da Cidade do México iniciado na década de 1980. Por meio do acúmulo de lixo nas ruas do coração da cidade, atesta não apenas a presença dos que se pretendia excluir, mas de seus resíduos indesejáveis.

A mobilização dos varredores, que acaba por formar uma barricada, nos endereça também às revoluções do século XIX. À época, grosso modo, as camadas oprimidas insurgentes - naquele momento parte dos operários e da burguesia - reivindicavam seu direito à participação política na Europa, destacadamente na França, em suas ruelas até então medievais. Não por acaso, as diversas barricadas levantadas entre os anos 1827 e 1849 foram um dos principais motivos - não necessariamente declarados - para a 
reforma urbana de Paris liderada pelo Barão Haussmann a pedido de Napoleão $3^{\circ}$. Desde então o vocabulário higienista é utilizado como mote de muitas transformações urbanas pretendidas pelos governos 1

As barricadas são, ainda hoje, um símbolo de resistência e de disputa pelo poder daqueles que se sentem excluídos do sistema, escanteados na vida pública. É curioso pensar que as largas avenidas (boulevards) criadas por Haussmann para combater as barricadas populares foram utilizadas pelas tropas nazistas durante a invasão a Paris. Também os garis que prestavam serviço à prefeitura da Cidade do México visando desobstruir as vias para garantir o fluxo urbano diário, naquela madrugada de 2004, realizaram o movimento inverso ao esperado. Mais uma vez nos projetos do artista a história mostra como os processos carregam consigo sempre a potência de sua inversão, quando a população reage de maneira inesperada, combatendo a ordem que se pretendia impor.

Em Barrenderos "forma-se uma linha, forma de representação que evoca uma coletividade e que, para Alÿs, parecia a forma mais efetiva de expressar a ideia fisicamente" (ALŸS; MEDINA, 2005, p. 30). A ideia de linha se faz presente em grande parte dos projetos de Alÿs, tanto de maneira individual - como em suas caminhadas - quanto de maneira coletiva. São linhas que não traçam limites, ao contrário, muitas vezes elas justamente subvertem esses limites, ou os deslocam para além. Conforme a situação, essas linhas ganham espessura e até mesmo tridimensionalidade.

Aqui trata-se de uma linha dupla: uma primeira, de corpos postos lado-a-lado com suas vassouras e uma segunda, resultante da ação da primeira, feita do acúmulo de lixo. Quanto maior se torna a segunda tanto mais difícil se torna para a primeira avançar, até o momento em que a segunda se converte em intransponível e seu volume supera o da primeira. Ao final, criatura torna-se maior do que 
criador, por assim dizer. O processo pode ser lido como uma alegoria ao próprio modus operandi de Alÿs, que em sua trajetória parece cada vez mais se deixar contaminar pelos colaboradores e processos que dispara. Como o próprio artista sentencia, em sua entrevista a Russell Ferguson (2007), quando diz que busca provocar ações cujo roteiro seja suficientemente interessante para criar vida própria e extrapolar sua participação como autor, o convertendo em espectador do processo.

A operação segue um enunciado lançado pelo artista, porém passa a ser coordenada pelo próprio grupo: a partir de um certo ponto se perde a noção de sujeito ou hierarquia. Organiza-se uma partilha comum, um agenciamento coletivo que vai se conformando ao longo do processo. Ao final do vídeo que a registra, Alÿs comenta que a ação teve um desenrolar muito mais bonito do que ele tinha imaginado em seu projeto. Essa porosidade e imprevisibilidade alinham-se às ideias defendidas por Deleuze e Guattari e fazem parte das táticas de Alÿs, que promovem afetos e novas subjetividades àqueles que participam de suas propostas. "Além das demandas materiais e políticas, o que emerge é uma aspiração por reapropriações individuais e coletivas da produção de subjetividade" (GUATTARI, 2012, p. 81).

Tanto Barrenderos quanto outro projeto anterior do artista, chamado Los siete niveles (o las siete vidas) de la basura, remetem aos sucessivos níveis envolvidos nos ciclos de produção-consumo-descarte em cidades consideradas subdesenvolvidas. Nelas, o próprio processo de coleta do lixo se dá de maneira bastante informal e depende, muitas vezes, do trabalho de catadores. Em nenhum momento a postura de Alÿs ao investigar esses procedimentos soa moralista. Não se trata de uma obra-denúncia. Talvez seu entendimento esteja mais próximo a Certeau quando nos fala, com certa benevolência ou esperança, sobre as operações de apropriação dos usuários nas cadeias de produção e consumo promovidas pelas engrenagens do sistema 
capitalista.

Segundo Certeau "para ler e escrever a cultura ordinária é mister reaprender operações comuns e fazer da análise uma variante de seu objeto" (1994, p. 35). Seu entendimento desloca o consumidor passivo para o papel de usuário subversivo; postula que o foco de interesse não deve residir nos produtos oferecidos no mercado, outrossim na maneira como os usuários os operam gerando desvios sociais com suas práticas. Declara-se instigado com a "'proliferação disseminada' de criações anônimas e 'perecíveis' que irrompem com vivacidade e não se capitalizam" (CERTEAU, 1994, p. 37). Visto que seu livro $A$ invenção do cotidiano fundamenta-se em pesquisa desenvolvida na França, durante a década de 1970, é importante pensarmos que esse tipo de operação que o autor considera como uma tática astuta da população anônima é muitas vezes, para nós latino-americanos, uma forma de sobrevivência. De qualquer forma, tanto Alÿs como Certeau parecem identificar nessas experiências anônimas "as inquietações, as solidariedades e as lutas que organizam o espaço onde essas narrações vão abrindo um caminho" (CERTEAU, 1994, p. 35).

Alÿs revela essa tensão entre operações táticas e ações estratégicas por meio de seus trabalhos que propõe outras formas de apropriação: do lixo, do espaço público, do tempo nas cidades. O conceito de desperdício e de resíduos gerados pelo sistema é o ponto de partida para muitos de seus projetos. Poderia se dizer, inclusive, que ao fazer uma proposição formal, criando uma espécie de escultura com o lixo, Alÿs estria um espaço dantes liso, informando-o. Ao mesmo tempo, alisa a ação de trabalhadores ao propor uma atividade que escapa completamente à função para a qual foram contratados.

O artista brinca, assim, com outros possíveis modelos de ocupação do tempo que fogem ao do trabalho. Propõe uma espécie de jogo aos varredores que se unem a partir de uma atividade lúdica, nos lembrando das sociedades indígenas da América Latina descritas 
por Deleuze e Guattari (1997) ao falarem do modelo-econômico do trabalho. Muitas vezes chamadas erroneamente de sociedades da preguiça, segundo os autores franceses, eram sociedades de ação livre, de espaço liso, que desprezavam a noção de excedente ou de acúmulo e que, por vezes, preferiam deixar-se morrer a realizar trabalhos forçados. É uma postura de alisamento extremo frente a um sistema opressor que visa impor suas regras sem deixar espaço para atividades criadoras como as propostas por Alÿs.

No filme que registra a ação, Alÿs declara que as coisas saíram diferentes do que ele havia planejado e que, ao fugir de seu controle, ele se sentiu aliviado. Segundo o artista, cada nova situação proposta tem essa qualidade no México, visto que sua população sempre the surpreende, fazendo com que ele deva aprender algo novo a cada vez. Certeau, Deleuze e Guattari poderiam identificar nesse depoimento aquilo que defendem sobre o comportamento resistente da população anônima que habita as cidades a seu modo, alisando as estrias do sistema.

É curioso, nesse sentido, outra fala que ouvimos no início da filmagem, no diálogo entre Francis e Cuauhtémoc, em que o artista explica a seu amigo que foi necessário pedir que um carro de polícia os acompanhasse para lhes proteger da própria polícia. Essa imagem pode nos remeter à constante disputa pelo domínio do espaço público entre o poder constituído - com suas estratégias de controle e repressão - e as táticas que burlam esse sistema, como as criadas pelos trabalhadores informais, ou aquelas encontradas dentro do próprio sistema, com seus desvios e corrupções internas. Alÿs contribui para apontar dissensos presentes naquele cenário, expondo idiossincrasias e revelando sujeitos e formas de expressão ainda não exploradas nesse locus político. Tanto em Cuando la fe mueve montañas como em Barrenderos a ficcionalidade é, como afirma Rancière, "a potência de significação inerente às coisas mudas e a potencialização dos discursos e dos níveis de significação" (2009, p. 55). O autor segue ainda indicando que "arte e política têm em 
comum o fato de produzirem ficções. Uma ficção não consiste em contar histórias imaginárias. É a construção de uma nova relação entre a aparência e a realidade, o visível e o seu significado, o singular e o comum" (RANCIÈRE, 2005, s.p.).

A ação promove um modo de compartilhamento do sensível em torno de uma proposta absurda, mas extremamente política em sua beleza deslocada. Alÿs ajuda a criar as condições necessárias para que a forma resulte de tensões internas ao processo em si e não de um desenho autoral, feito a priori: não-artistas são incitados a dar forma ao objeto de seu trabalho, a coreografarem uma dança expressiva, que culmina com a conformação de um corpo intransponível, moldando novas relações. Nas palavras do próprio artista, trata-se de um tipo de arte que "pode fortalecer indivíduos para, de alguma forma, modificar as configurações sócio-políticas de um coletivo" (ALŸS; MEDINA, 2005, p. 25).

É importante perceber o quanto esses dois projetos, de 2002 e 2004, marcam um esgarçamento no raio de atuação do artista que dá conta de situações cada vez mais marginais, pode-se dizer. Alÿs também passa a desenvolver projetos envolvendo mais participantes, mais voluntários, que ganham mais relevância e significado nas ações a partir daquele momento. O cenário das megalópoles áridas de Lima ou da Cidade do México dão lugar a paisagens litorâneas em dois projetos similares entre si que o artista desenvolve nos anos seguintes, corroborando para essa percepção: Puente, de 2006 e Don't cross the bridge before you get to the river, de 2008. Mais do que uma ampliação em termos territoriais ou de envolvimento social, o que torna esses trabalhos especiais na trajetória de Alÿs é o entendimento do artista de que suas ações podem assumir um papel político ou, segundo suas palavras, o poético pode se tornar político e o político se tornar poético. Já nas palavras de Rancière, "A política e a arte, tanto quanto os saberes, constroem 'ficções', isto é, rearranjos materiais dos signos e das imagens, das relações entre o que se vê e o 
que se diz, entre o que se faz e o que se pode fazer" (2009, p. 59, grifo do autor).

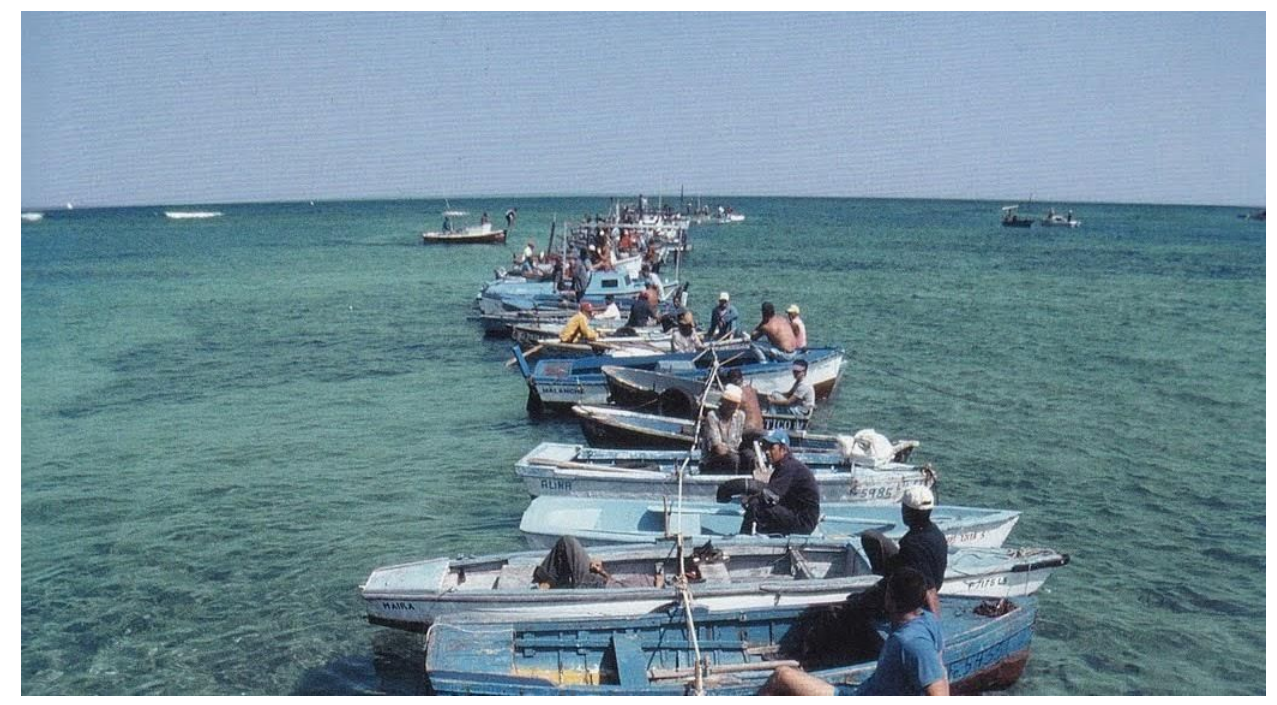

Figura : Francis Alÿs em colaboração com Tayana Pimentel e Cuauhtémoc Medina. Puente, 2006. Documentação fotográfica de um evento.

Fonte: FERGUSON; FISHER; MEDINA, 2007, p. 107.

Em Puente, Alÿs propõe a diferentes grupos de pescadores e velejadores a criação - a partir do enfileiramento de seus barcos casco a casco - de uma fila o mais longa possível, rumo à linha onde horizonte e oceano se dividem em dois tons de azul. Esse convite é feito em duas cidades que ocupam margens opostas, separadas por algumas milhas náuticas, no intuito secreto de formarem uma ponte. As cidades são Havana, em Cuba e Keywest, nos Estados Unidos. Já em Don't cross the bridge before you get to the river, em vez de pescadores ou velejadores, Alÿs incentiva crianças a formarem duas filas Mediterrâneo adentro, no Estreito de Gibraltar. Menos de $15 \mathrm{~km}$ separam os dois grupos infantis que, simultaneamente, entram no mar com seus barcos de brinquedo buscando se encontrar: um sai da praia de Tangier, no Marrocos, o outro de Tenerife, na Espanha.

Os dois trabalhos soam como duas imagens geradas a partir de um roteiro comum. Em ambas, a proposta é feita por Alÿs e seus 
colaboradores à população local, incitando à participação, mas sem revelar que a ação ocorre na margem oposta. A falta de objetivo declarado gera rumores e cria hipóteses narrativas diferentes em cada um dos voluntários, como podemos ver no vídeo que documenta a ação em Puente. Já o filme de Don't cross the bridge... não revela o início ou o fim do processo, apenas um contínuo meio, em progresso. No vídeo que registra a última ação, na verdade, sequer descobrimos até onde as crianças foram ou se chegaram a se encontrar no espaço entre as duas margens. Resta a dúvida.

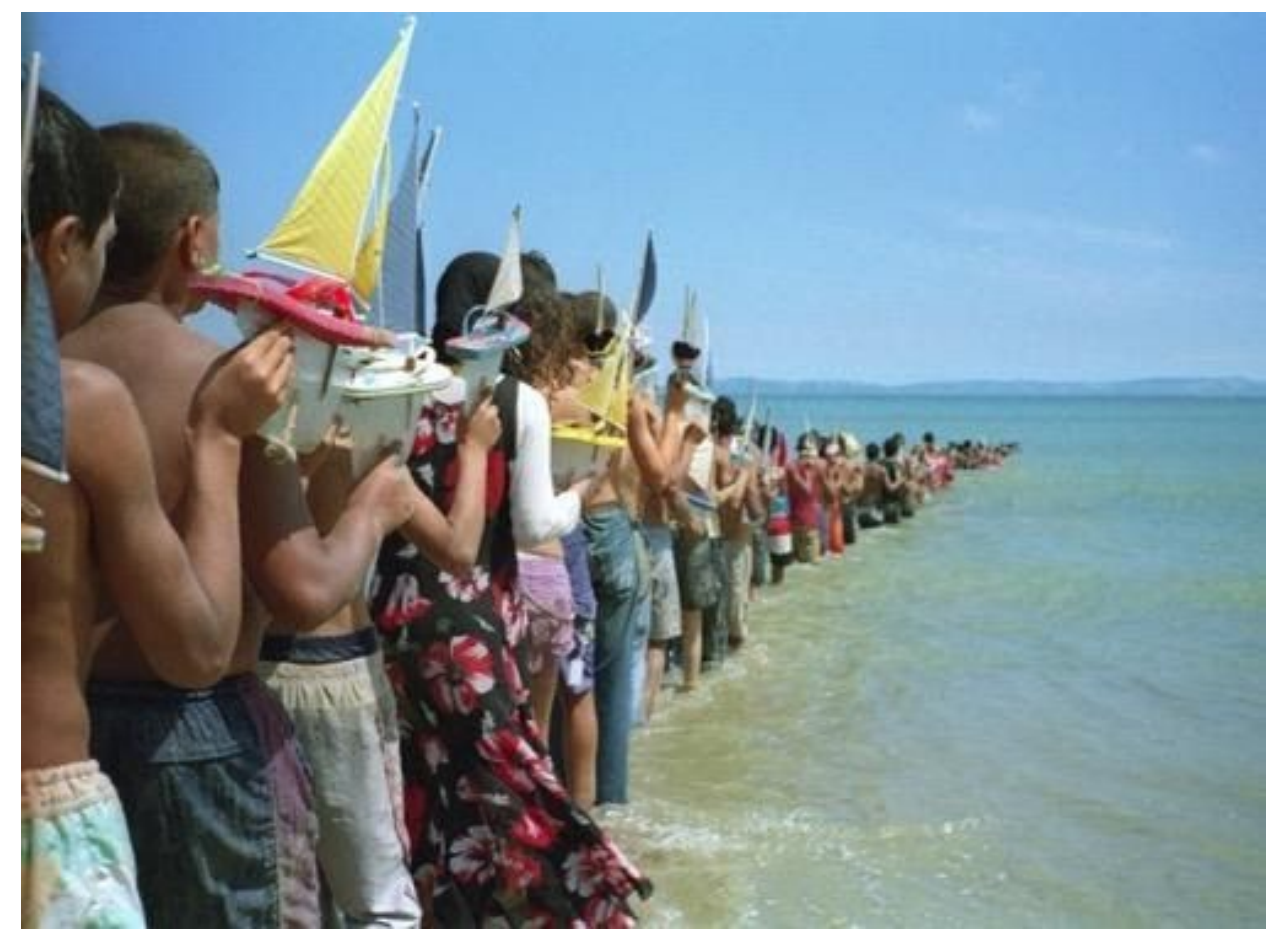

Figura 4: Francis Alÿs. Don't cross the bridge before you get to the river, 2008. Documentação fotográfica de uma ação.

Fonte:http://www.japantimes.co.jp/culture/2013/05/09/arts/replaying-peoples-action s-with-a-twist/

Alÿs utiliza os canais de fluxo que estão ao alcance da população de Cuba e dos EUA, da África e da Europa, espaços públicos de certa forma, para questionar as linhas muitas vezes invisíveis - nem por isso menos difíceis de cruzar - entre fronteiras. Propõe quebras nesses limites, possibilidades de escapar ao sistema. 
Expande, com isso, o conceito de espaço público para além das ruas e praças urbanas, alcançando as praias públicas, as águas de domínio público, o mar.

A ponte a ser construída coletivamente representa uma união tida por impossível, entre dois mundos de acentuadas diferenças culturais, políticas e econômicas. Trata-se de um roteiro que toma corpo na realidade a partir do ritual artístico: tão ficcional quanto as fronteiras geopolíticas que tantas vezes surgem a partir de desenhos arbitrados a separarem uma mesma comunidade em dois países. Por meio de sua proposta, Alÿs nos confronta com a criação de possibilidades não filtradas pelos consensos, pela repetição dos gestos existentes nem por suas barreiras. Além de registrar ou problematizar a gentrificação e o banimento de parte da população do espaço público e político da urbe, o artista busca realizar o movimento contrário. Em vez de permanecer no centro reclamando a presença daqueles que foram excluídos, vai a seu encontro, incentiva sua participação. Alÿs inventa novos espaços comuns, especializa as bordas e gera possibilidades de inclusão simbólica. Segundo ele, “não se mudou nada, mas se introduziu por algumas horas a possibilidade de mudança, para além do absurdo e futilidade do ato" (ALŸS; MEDINA, 2005, p. 105).

No vídeo que documenta Puente, logo no enunciado é declarada a assimetria entre a quantidade de barcos participando da ação no lado norte-americano (32), da mais de uma centena de embarcações cubanas. Não existem acordos e a negociação de onde parte o artista evidencia essa necessidade política em lidar com sujeitos plurais, não apenas em seus objetivos, mas em suas visões, identidades e papéis no projeto proposto e no contexto existente. O dissenso estende-se também ao imaginário dos participantes, que mentalmente completam o roteiro sem fim proposto por Alÿs, como podemos ver pelos depoimentos filmados.

Rancière escreve que o conceito de vanguarda artística só faz sentido quando temos a "invenção de formas sensíveis e dos limites 
materiais de uma vida por vir" (2009, p. 43). Criar pontes é o que fazem nossos pensamentos, gerando novas sinapses, associações e significados possíveis para conceitos já existentes e para aqueles que ainda virão a ser. O mesmo procedimento é incentivado por Alÿs, buscando novas formas de pensabilidade sobre uma situação já não mais questionada em seus fundamentos. De acordo com Rancière, no atual momento - a era da estética - "escrever a história e escrever histórias pertencem a um mesmo regime de verdade" (RANCIÈRE, 2009, p. 58).

Desnaturalizar a certeza de que Cuba e EUA ou de que África e Europa são realidades completamente distintas, inconfundíveis e apartadas, é uma provocação que Alÿs lança com suas ações. Como o filósofo insiste: a arte pode ser um elemento de "transformação do pensamento em experiência sensível da comunidade" (RANCIÈRE, 2009, p. 67). A ideia de comunidade, cuja raiz etimológica nos remete a um comum, é o ponto de partida desses trabalhos do artista. Alÿs propõe a união de grupos heterogêneos sem negar os desequilíbrios e desacordos: são novas possibilidades de subjetivação e de desnaturalização do que é partilhado entre essas comunidades.

Ao propor ações processuais em que o percurso torna-se mais importante do que o ponto de partida ou o de chegada, Alÿs nos remete à diferença entre liso e estriado proposta por Deleuze e Guattari, quando afirmam que um e outro se diferenciam, antes de mais nada, pela relação inversa do ponto e da linha. No espaço estriado parte-se de dois pontos entre os quais desenha-se uma linha, enquanto no liso o que importa são os pontos que configuram o desenho da linha. Segundo os autores:

No espaço estriado, as linhas, os trajetos têm uma tendência a ficar subordinados aos pontos: vai-se de um ponto a outro. No liso, é o inverso: os pontos estão subordinados ao trajeto. É a subordinação do habitat ao percurso, a conformação do espaço do dentro ao espaço do fora: a tenda (nômade), o iglu, o barco. [...] O espaço liso é ocupado por acontecimentos ou hecceidades, muito mais do que por coisas formadas e percebidas. É um espaço de afetos mais do que de propriedades. É uma percepção háptica, mais do que óptica. É um espaço intensivo mais do que 
extensivo, de distâncias e não de medidas. O que ocupa o espaço liso são intensidades, os ventos e ruídos, as forças e qualidades tácteis e sonoras, como no deserto, na estepe ou no gelo. O que cobre o espaço estriado, ao contrário, é o céu como medida (astronômica), e as qualidades visuais mensuráveis que derivam dele. (DELEUZE; GUATTARI, 1997, v. 5, p. 184).

O artista propõe a criação de duas linhas, mas o que interessa é a possibilidade de uma intersecção entre elas, um cruzamento no horizonte. Vale entender essa intersecção imaginária de linhas a partir dos pensadores franceses quando defendem que:

\begin{abstract}
Nada coincide inteiramente e tudo se mistura ou passa de um para outro [...]; pode-se habitar os desertos ou mares de modo estriado; pode-se habitar de um modo liso inclusive as cidades, ser um nômade das cidades. [...] Em suma, o que distingue a viagem não é a qualidade objetiva dos lugares, nem a quantidade mensurável do movimento - nem algo que estaria unicamente no espírito - mas o modo de espacialização, a maneira de estar no espaço, de ser no espaço. (DELEUZE; GUATTARI, 1997, v. 5, p. 190).
\end{abstract}

Certeau faz uma diferenciação importante nesse sentido, ao conceituar o termo espaço como um lugar praticado. Enquanto um lugar seria "uma configuração instantânea de posições [...]" (1994, p. 201), indicando fixidez e relações de ordem referenciadas, a ideia de espaço implicaria fluxos, cruzamentos e estaria atrelada à de mobilidade. Se adotamos neste artigo o conceito de espaço para analisar as ações realizadas por Alÿs é justamente por entender que se tratam de deslocamentos operando na configuração do tempo-espaço urbano. São práticas instauradas por movimentos que não se submetem às linhas estratégicas que criam os lugares e os mantêm estáveis, como mapas.

Vale aqui resgatar, aliás, alguns dados acerca de mapas e da própria denominação original de atlas que, como comenta Certeau (1994), atendia originalmente pelo nome de teatro. Somente após a intervenção da geometria - inicialmente euclidiana e atualmente descritiva - é que o conjunto de mapas e a própria ideia de mapa foram paulatinamente perdendo seu vínculo com as atuações, com a vida social que neles tomava forma, deixando de ser teatro para ser 
atlas. Tornaram-se distantes, abstratos, com pretensões totalizantes. Cabe recordar ainda que o próprio nome atlas foi cunhado a partir de Mercator $^{2}$, cartógrafo responsável pela representação mais usual do globo terrestre em duas dimensões até hoje - onde a Europa ocupa o centro do mapa e suas dimensões são exageradas em relação ao tamanho natural, enquanto a África é reduzida, por exemplo.

Essa cientifização falsamente neutra acarreta um afastamento entre a cidade das representações e aquela das apropriações. A primeira passa a ser descrita através de um quadro estático, enquanto a segunda necessariamente envolve atos. Na primeira, algo está à direita, ao norte ou a três quilômetros; na segunda, se dobra à direita, se caminha rumo ao norte, se percorrem três quilômetros. Ao inserir a possibilidade de pontes que dependem do movimento das pessoas para existir, Alÿs funde essas duas formas de aproximação, recria a conexão e retoma, a partir de um mapa, o teatro que nele toma parte. 


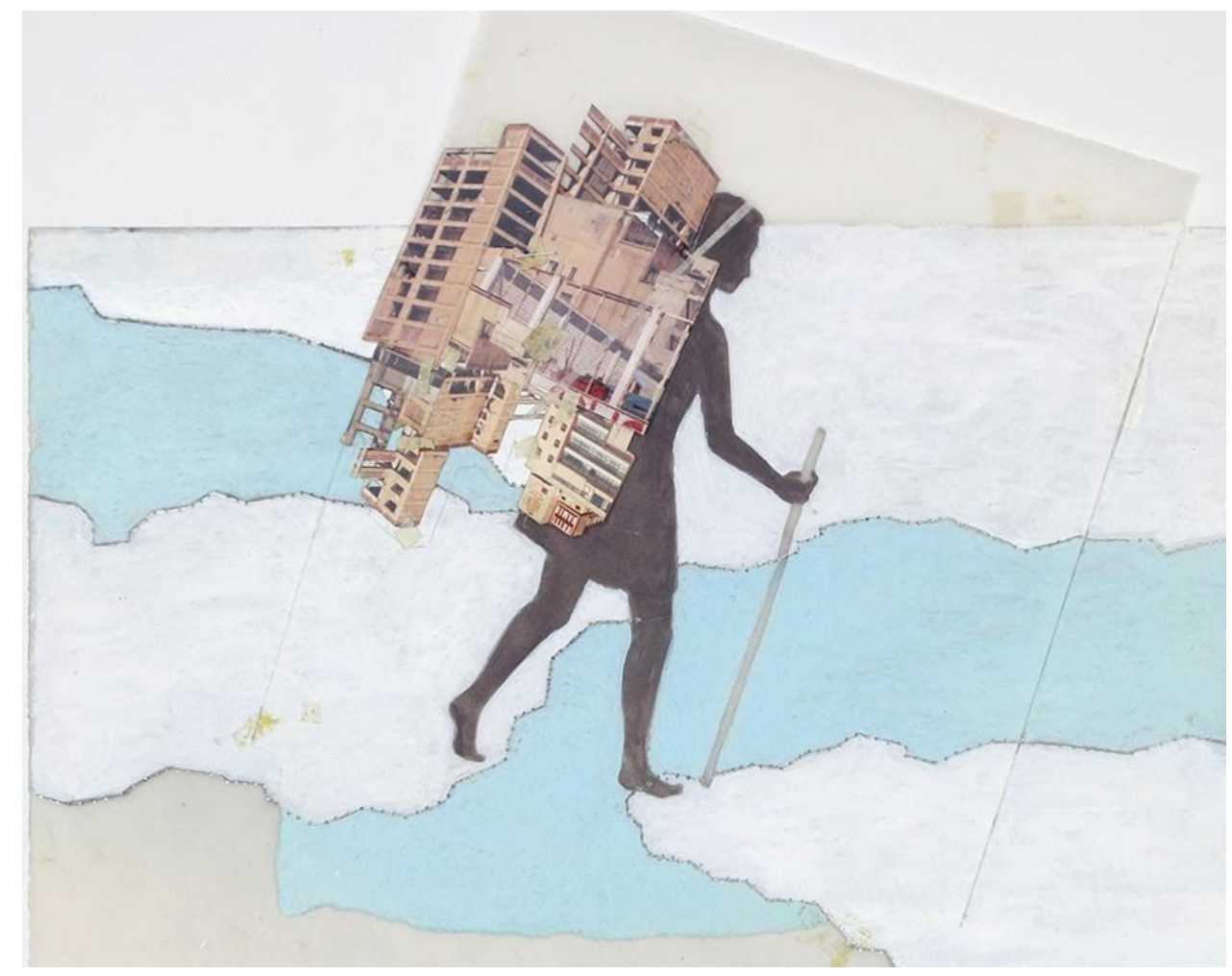

Figura 5: Francis Alÿs. Don't cross the bridge before you get to the river, 2008.

Documentação gráfica de uma ação.

Fonte: http://museotamayo.org/artista/francis-alys

Quando elabora um roteiro em que a linha que constitui a ponte se desfaz, propositalmente, ao final da ação, Alÿs declara que não pretende construir uma ponte real, torná-la um novo lugar na paisagem, uma linha no mapa. Converte outrossim o lugar que caracteriza a fronteira em um espaço, o cria a partir de seu enunciado poético e da ação que o sucede. Certeau disserta que ali onde os relatos deixam de existir há uma perda de espaço, uma tendência à museificação das cidades, privadas de suas práticas narrativas. "No relato, a fronteira funciona como um terceiro. Ela é um 'entre dois' 'um espaço entre dois"' (CERTEAU, 1994, p. 213).

O enunciado que acompanha o vídeo em Don't cross the bridge... revela que a intenção do artista não era a de conectar Espanha e Marrocos através de engenharia náutica, o que não seria tão difícil, visto que distam apenas treze quilômetros no Estreito de 
Gibraltar. Alÿs convida crianças para levarem seus barcos de chinelo como uma ação ritualística. Ao mudar a escala de barcos de verdade para aqueles de brinquedo, faz "crescer" as crianças, como se fossem monstros mitológicos que habitam as águas. O aspecto ficcional da ação que surge a partir de um roteiro que não se fecha é reiterado pelas formas de visibilidade que Alÿs e seus colaboradores proporcionam nesses dois trabalhos. Não sabemos se as linhas se tocaram no horizonte - restam a curiosidade, os rumores, a fábula. No projeto realizado no estreito de Gibraltar, a questão surge como pergunta no início do filme que promete, mas não conta o fim. Conforme as crianças avançam, a câmera mergulha, perde-se na água e o movimento parece repetir-se a cada vez que se aproxima de uma conclusão. Segundo Alÿs (2010), trata-se de “um presente a ser continuado."

\section{Em fluxo}

Quando começou sua carreira artística, Alÿs partiu de pequenas intervenções, inicialmente em janelas de prédios, depois na rua, na praça central da cidade, até chegar ao limite do urbano e, finalmente, na fronteira entre terra e mar. Não se trata de um movimento linear e unidirecional para fora nem de uma evolução: Alÿs segue retornando. Porém, o alcance de seus rituais se amplia ao longo de sua trajetória. Acompanhamos o artista nesse movimento e passamos a perceber o espaço público urbano não mais como a rua ou a praça no centro da cidade - alargamos nossa concepção para abarcar o perímetro da megalópole, as dunas de areia, o litoral como espaços comuns. Se Alÿs caminha rumo às fronteiras, nós o seguimos e levamos o conceito do que é urbano conosco.

Aqui vale insistir que a cidade não é apenas o espaço, é também o tempo em que as ações sociais se projetam. Para além de um esgarçamento no território de suas fábulas, Alÿs gera aberturas de um tempo dentro de outro - uma temporalidade não linear, não cronológica. Por meio de movimentos cíclicos e quase hipnóticos, 
emerge um tempo heterogêneo, feito de hecceidades. O que vemos não é um simples looping, em que uma mesma ação e imagem se repetem à exaustão, mas sim diferentes andamentos: avançar e recuar, fazer e desfazer. Outros ritmos, aparentemente circulares, porém sutilmente heteróclitos, insurgem e reclamam sua duração nesse presente a ser continuado. Ficamos em suspensão acompanhando os gestos que seguem: nosso raciocínio busca fechamentos. Nossa mente nos ilude, e permanecemos compenetrados, numa atenção flutuante, atraídos pelo suspense e pela esperança de um fim que nunca chega.

A poética de Alÿs parece impregnada por essa temporalidade cíclica - seja como alusão ao dogma do progresso, às rotinas diárias ou ao vai-e-vem de fatos históricos e políticos. Em seus trabalhos o movimento se refaz com pequenas variações: no roteiro, no local de realização, na forma de registrá-lo ou fazê-lo reverberar. A repetição torna-se algo que Deleuze considera transformador, por expressar “[...] ao mesmo tempo, uma singularidade contra o geral, uma universalidade contra o particular, um extraordinário contra o ordinário [...] Em todos os sentidos, a repetição é transgressão" (1988, p. 24). 


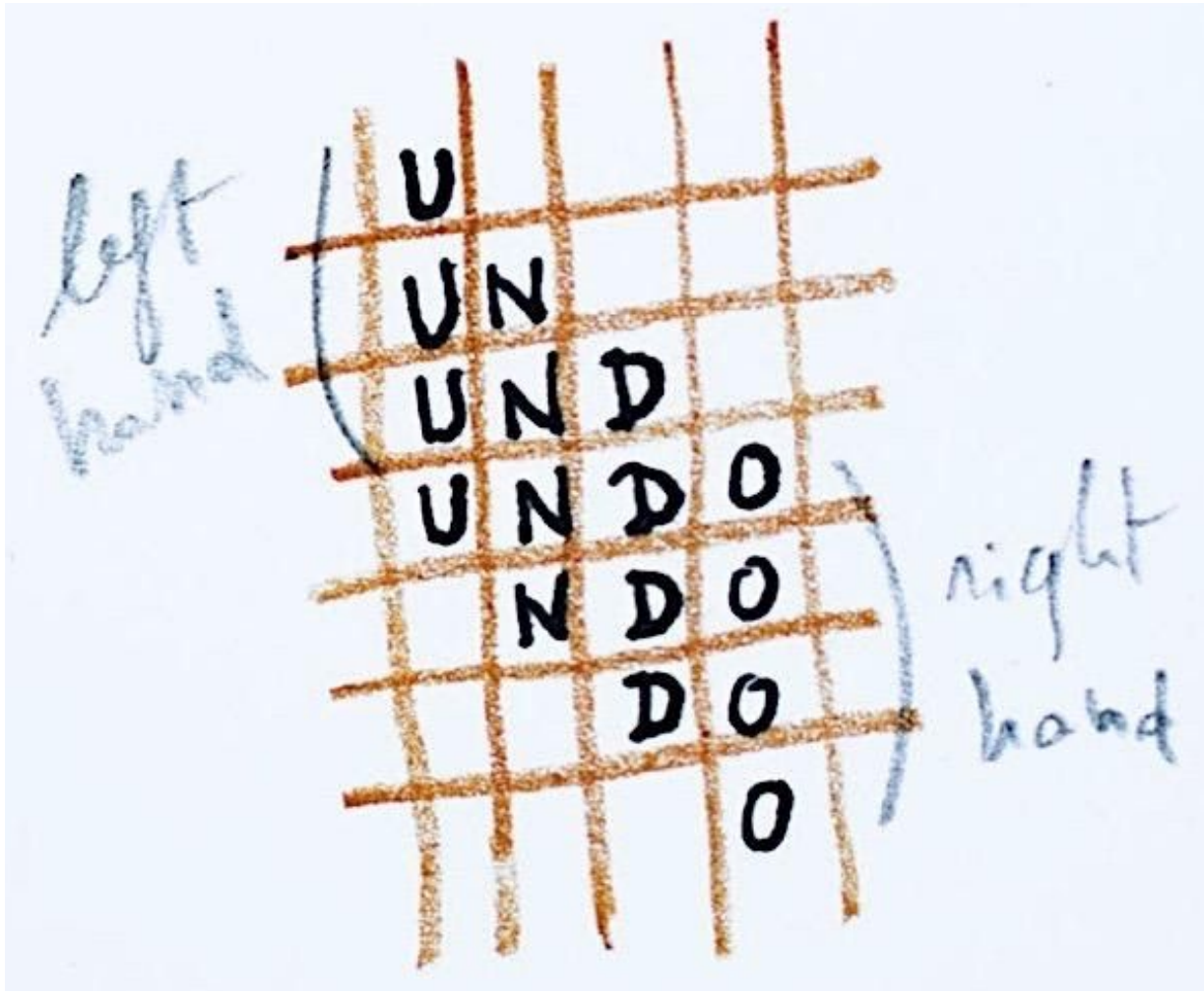

Figura 6: Francis Alÿs. Desenho do artista.

Fonte: ALŸS, 2010, s.p.

O quanto preciso repetir algo para torná-lo um processo meu, naturalizado? Na cidade embalada por movimento pendulares, por trajetos que se fazem todos os dias, quais gestos podem levar a lugares outros, extrapolar os limites? Talvez não se trate do que fazer, mas de como fazer. Segundo Deleuze e Guattari, trata-se do modo de espacialização. Para Certeau "onde o mapa demarca, o relato faz uma travessia [...] instaura uma caminhada (guia) e passa através (transgride). O espaço de operações que ele pisa é feito de movimentos: é topológico, relativo às deformações de figuras e não tópico (definidor de lugares)" (1994, p. 215).

Quando escreve sobre delinquências e coloca um ponto de interrogação ao lado da palavra, Certeau (1994) nos interroga, pois sua figura do delinquente seria a daquele ou daquilo que vive nos interstícios, sempre em movimentos contrários ao da estratégia, desmanchando e deslocando suas barreiras, gerando espaços topológicos. Com seus passeios e rituais desviantes - seja ao 
bloquear uma rua com seu lixo, deslocar uma duna ou propor a construção de pontes fabulosas entre países e continentes em conflito - Alÿs transgride.

Entre o aprisionamento em padrões e alinhamentos disciplinares - caracterizado por agendas funcionais, espaços públicos programáticos, cidades claustrofóbicas e burocráticas, barreiras nacionais e xenofobia - e o desvio na ilegalidade com sua errância perpétua, existiria uma delinquência possível? Como se daria uma narrativa delinquente compatível com esse movimento de estar ao mesmo tempo inserido e fora da sociedade e de suas regras, da cidade e de seu planejamento? Certeau acredita que o corpo em movimento na urbe seja o primeiro passo dessa narrativa. Alÿs, em sua trajetória poética, reforça essa ideia, compartilhada também por Deleuze e Guattari.

Ao criar linhas com resíduos, voluntários ou barcos, o artista nos recorda que os traçados político-geográficos são arbitrários em sua maioria e que será o uso ao longo do tempo a reforçar ou borrar essas linhas. Como podemos, em nossas práticas urbanas, cancelar ou ignorar divisas que controlam nossa circulação? Alÿs não suprime as fronteiras, mas desfataliza sua existência, questiona sua perenidade, permite uma atitude menos reverente frente aos limites impostos - na arte, na cidade, na política. Talvez esse seja um caminho.

Poderíamos, portanto, caminhar tanto sobre as linhas divisórias a ponto de gastá-las, de apagá-las ou, no mínimo, de espessá-las e torná-las um novo espaço. Deixar-se ficar nas bordas seria uma opção para desafiar os acordos, gerar atritos, para sairmos do terreno seguro do familiar. Por que não nos colocamos nesse papel de estrangeiros em nosso dia a dia? Que exercícios seriam necessários para nos desanestesiarmos e estarmos receptivos ao estranhamento? O quanto nos custa deixar morrer nossas certezas e com isso liberarmos espaço para a criação do novo? Desterritorializar para então reterritorializar nossa própria vida. Além de espessarmos 
ou borrarmos os limites em ações delinquentes, nômades, de que forma a cidade pode ajudar nesse processo, permitir aberturas e mudanças?

Alÿs não pretende deixar um legado - como uma herança cultural a ser entregue - a uma cidade ou comunidade, nem pressupõe que aqueles que entram em contato com seus trabalhos prescindam das capacidades necessárias à sua fruição. Ao contrário, o artista provoca novas experiências estéticas para partilhar o sensível, sem distinção. Mesmo sem estar seguro a respeito de sua capacidade de transformação real ou imediata, segue provocando, com seus gestos micropolíticos, pequenas perturbações na partilha do visível, fazível e pensável. Citando novamente sua frase “[...] não se mudou nada, mas se introduziu por algumas horas a possibilidade de mudança" (ALŸS; MEDINA, 2005, p. 105).

O presente trabalho foi realizado com apoio da Coordenação de Aperfeiçoamento de Pessoal de Nível Superior - Brasil (Capes) Código de Financiamento 001 a Paulo Reyes e bolsa de doutorado PROEX/CAPES a Germana Konrath. 


\section{Referências}

ALŸS, Francis. Numa dada situação/ In a given situation. São Paulo: Cosac Naify, 2010.

ALŸS, Francis; MEDINA, Cuauhtémoc. Cuando la fe mueve montañas/ When Faith Moves Mountains. Madri: Turner, 2005

BENEVOLO, Leonardo. História da Cidade. São Paulo: Perspectiva, 1983.

CANCLINI, Néstor García. A sociedade sem relato: Antropologia e Estética da Iminência. São Paulo: Edusp, 2012.

CERTEAU, Michel de. A invenção do cotidiano 1: Artes de fazer. Petrópolis: Editora Vozes, 1994.

DELEUZE, Gilles. Diferença e repetição. Rio de Janeiro: Graal, 1988.

DELEUZE, Gilles; GUATTARI, Félix. Mil Platôs: Capitalismo e esquizofrenia, v. 5. São Paulo: Editora 34, 1997. 5 v.

FERGUSON, Russell; FISHER, Jean. MEDINA, Cuauhtémoc. Francis Alÿs. Londres: Phaidon, 2007.

GUATTARI, Félix. Caosmose: um novo paradigma estético. São Paulo: Editora 34, 2012.

KONRATH, Germana. Às vezes fazer algo poético pode se tornar político e às vezes fazer algo político pode se tornar poético: a ocupação do tempo e do espaço na poética urbana de Francis Alÿs. 2017. 247 f. Dissertação (Mestrado em Planejamento Urbano e Regional) - Faculdade de Arquitetura e Urbanismo, UFRGS, Porto Alegre, 2017.

LEFEBVRE, Henri. O direito à cidade. 5. ed. São Paulo: Centauro, 2008.

RANCIÈRE, Jacques. Política da arte. In.: São Paulo S.A. - práticas estéticas, sociais e políticas em debate. São Paulo: Sesc, 2005.

. A partilha do sensível: estética e política. 2. ed. São Paulo: Editora 34, 2009.

<http://www.francisalys.com/>. Acesso em: 24 jul. 2019.

\section{Resumo}

Francis Alÿs, artista belga naturalizado mexicano, tem uma poética notoriamente urbana e intimamente ligada à sua formação como arquiteto. Seus trabalhos, contudo, não são pautados pelos princípios vitruvianos de firmitas, tampouco de utilitas, e mesmo a beleza (ou venustas) de suas ações destoa dos cânones da história da arte. A trajetória de Alÿs emerge de fábulas que dão vida a rituais de desterritorialização-reterritorialização inventados pelo artista para cada cidade por que passa. Este texto propõe um diálogo entre trabalhos onde Alÿs molda o 
DOI:10.20396/urbana.v11i3.8656083

espaço-tempo comum através da participação coletiva e aportes teóricos de Jacques Rancière, Michel de Certeau e da dupla Gilles Deleuze e Félix Guattari. Interessa aqui problematizar as contribuições estéticas - e portanto políticas - de Alÿs, particularmente em situações de fronteira, tanto físicas quanto simbólicas, da cidade contemporânea.

Palavras-chave: Fronteiras urbanas. Francis Alÿs. Espaço-tempo comum.

\begin{abstract}
Francis Alÿs, a Belgian naturalized Mexican artist, has a notoriously urban poetic that is closely related to his background as an architect. His works, however, are not guided by the Vitruvian principles of firmitas nor utilitas - and even the beauty (or venustas) of his actions is at odds with the canons of Art History. Alÿs' trajectory emerges from fables that bring to life the rituals of deterritorialization-reterritorialization invented by the artist for every city he goes through. This text put into dialogue works in which Alÿs shapes common time-spaces through collective participation, with theoretical legacy by Jacques Rancière, Michel de Certeau and the duo Gilles Deleuze and Félix Guattari. It is our interest to discuss the aesthetic - and therefore political contributions of Alÿs, particularly in physical and symbolic border situations of the contemporary city.
\end{abstract}

Keywords: Urban borders. Francis Alÿs. Common time-space.

\title{
Resumen
}

Francis Alÿs, artista belga naturalizado mexicano, tiene una poética notoriamente urbana y estrechamente vinculada a su formación como arquitecto. Sin embargo, sus obras no están regidas por los principios vitruvianos de firmitas ni utilitas - e incluso la belleza (o venustas) de sus acciones está en desacuerdo con los cánones de la historia del arte. La trayectoria de Alÿs surge de fábulas que dan vida a los rituales de desterritorialización-reterritorialización inventados por el artista para cada ciudad que atraviesa. Este texto propone un diálogo entre obras donde Alÿs da forma a espacios-tiempos comunes a través de la participación colectiva con el legado teórico de Jacques Rancière, Michel de Certeau y el dúo Gilles Deleuze y Félix Guattari. El interés aquí es discutir las contribuciones estéticas - y por lo tanto políticas - de Alÿs particularmente en situaciones de frontera, tanto físicas como simbólicas, de la ciudad contemporánea.

Palabras clave: Fronteras urbanas. Francis Alÿs. Espacio-tiempo común. 